\title{
A hidden footprint: embryological origins of age related macular degeneration
}

\author{
Glen Jeffery ${ }^{1} \cdot$ Sobha Sivaprasad $\mathbb{B D}^{1}$
}

Received: 13 February 2019 / Accepted: 22 February 2019 / Published online: 17 April 2019

(c) The Royal College of Ophthalmologists 2019

There is something in the age related macular degeneration (AMD) story that does not fit comfortably within the framework of an ageing disease. First, in those with complement polymorphisms, which accounts for $50 \%$ of sufferers, abnormal choroidal blood flow occurs decades before disease .initiation [1]. Second, choroidal inflammation is present at similar early stages [2]. Likewise, early disease manifestations occur in complement factor $\mathrm{H}$ knock out mice. Here there is a significant decline in retinal adenosine triphosphate (ATP), which occurs long before a retinal phenotype appears [3, 4]. Reduced ATP signals senescence, and with its high metabolic demand, such a decline likely heralds trouble for the retina. These events imply that complement disruption impacts much earlier than expected. But we should not be surprised. Complement is a player in CNS development [5]. Further, complement factor H (CFH) is expressed in the retinal pigmented epithelium (RPE), which during development is the ventricular margin where neuronal cell division occurs. The RPE guides retinal development by regulating the cell cycle and signalling cycle exit. Along its outer surface it guides choroidal development. Hence, in the eye complement and development are linked via the RPE [6, 7].

To address this, Sivapathasuntharam et al. [8] examined retinal development in $\mathrm{Cfh}-/-$ and $\mathrm{Cfh}+/-$ mice and showed significant disruptions at the retinal/RPE interface. However, after retinal differentiation there are no obvious deficits. But when mitochondria are examined in the newly differentiated tissue abnormalities are obvious, matching subsequent reductions in ATP and abnormalities in the ERG [8].

As cell cycle exit point is critical in determining cell fate [9], it is likely that abnormalities exist in retinal cell populations and/or their patterns of connectivity as a

Glen Jeffery

g.jeffery@ucl.ac.uk

1 Institute of Ophthalmology, University College London, London, UK consequent of complement reduction. Likewise, there are probably differences in chordal architecture/function that harbour vulnerability exploited by age. Interestingly, these mice do not develop a retinal phenotype when kept in a pathogen free environment [10]. Hence, exploitation by age and environment are needed for disease progression.

Those with polymorphism of complement remain largely hidden without genotyping. Given the deficits revealed already $[1,2]$ it is likely that psychophysical or physiological investigations may show differences that distinguish these people whose problems may originate before birth.

Acknowledgements Supported by Biotechnology and Biological Science Research Council grant BB/N000250/1.

\section{Compliance with ethical standards}

Conflict of interest The authors have no conflict of interest.

Publisher's note: Springer Nature remains neutral with regard to jurisdictional claims in published maps and institutional affiliations.

\section{References}

1. Told R, Palkovits S, Haslacher H, Frantal S, Schmidl D, Boltz A, et al. Alterations in choroidal blood flow regulation in young healthy subjects with complement factor $\mathrm{H}$ polymorphisms. PLoS ONE. 2013;E60424:1-6.

2. Mullins RF, Dewald AD, Streb LM, Wang K, Kuehn MH, Stone EM. Elevated membrane attack complex in human choroid with high risk complement factor H genotypes. Exp Eye Res. 2011;93:565-7.

3. Coffey PJ, Gias C, McDermott CJ, Lundh P, Pickering MC, Sethi C, et al. Complement factor $\mathrm{H}$ deficiency in aged mice causes retinal abnormalities and visual dysfunction. Proc Natl Acad Sci USA. 2007;104:16651-6.

4. Cazala KC, Kam JH, Hogg C, Jeffery G. Mitochondrial decline precedes phenotype development in the complement factor $\mathrm{H}$ mouse model of retinal degeneration but can be corrected by near infrared light. Neurbiol Aging. 2015;36:2869-76.

5. Stevens B, Allen NJ, Vazquez LE, Howell GR, Christopherson $\mathrm{KS}$, Nouri N, et al. The classical complement cascade mediates CNS synapse elimination. Cell. 2007;131:1164-78. 
6. Jeffery G. The retinal pigmented epithelium as a developmental regulator of the neural retina. Eye. 1998;12:499-503.

7. Zhao S, Overbeek PA. Regulation of choroid development by the retinal pigment epithelium. Mol Vis. 2001;7:277-82.

8. Sivapathasuntharam C, Hayes M, Shinhmar H, Hoh Kam J, Sivaprasad S, Jeffery G. Complement factor $\mathrm{H}$ regulates retinal development and its absence may establish a footprint for age related macular degeneration. Sci Rep. 2019; 9:1082.

9. Dyer MA, Cepko CL. Regulating proliferation during retinal development. Nat Neurosci Rev. 2001;2:333-42.

10. Hoh Kam J, Morgan JE, Jeffery G. Aged complement factor $\mathrm{H}$ knockout mice kept in a clean barriered environment have reduced retinal pathology. Exp Eye Res. 2016;149:116-25. 